\title{
Predictors of Participation in the Family Check-Up Program: A Randomized Trial of Yearly Services from Age 2 to 10 Years
}

\author{
Justin D. Smith, \\ Center for Prevention Implementation Methodology, Northwestern University Feinberg School of \\ Medicine \\ Cady Berkel, \\ REACH Institute, Arizona State University
}

Katherine A. Hails,

University of Pittsburgh

Thomas J. Dishion, REACH Institute, Arizona State University \& Oregon Research Institute

Daniel S. Shaw, and

University of Pittsburgh

Melvin N. Wilson

University of Virginia

\begin{abstract}
A key challenge of community-based prevention programs is engaging families in the context of services settings involving children and families. The Family Check-Up (FCU) program is designed to engage families in parenting support appropriate to their level of need by use of assessment-enhanced motivational interviewing. This study involved families screened for risk who were seeking services at Women, Infant and Children's offices in three geographical regions $(\mathrm{N}=731)$. Families in the randomized intervention group ( $\mathrm{N}=367)$ were offered the FCU yearly, from age 2 through 10 . The results of multivariate modeling indicated that caregivers reporting high levels of perceived caregiving stress (i.e., depression, low parenting satisfaction, daily hassles) participated at a higher rate in two critical components (feedback and follow-up support interventions) of the FCU program over the 8-year trial period than caregivers reporting lesser degrees of stress. The implications of these findings are discussed in the context of familycentered programs for the prevention of child behavior problems and directions for future research.
\end{abstract}

Address correspondence to Justin D. Smith, Center for Prevention Implementation Methodology, Department of Psychiatry and Behavioral Sciences, Northwestern University Feinberg School of Medicine, 750 N Lake Shore Dr., Chicago, IL 60657. jd.smith@northwestern.edu.

Conflict of Interest. Thomas Dishion is the developer of the Family Check-Up program. Justin Smith, Cady Berkel, Katherine Hails, Daniel Shaw, and Melvin Wilson have no conflicts of interest or financial relationships relevant to this article to disclose.

Ethical Approval. All procedures performed in this study were approved by the Institutional Review Boards of the Arizona State University, the University of Oregon, the University of Pittsburgh, and the University of Virginia and were in accordance with the ethical standards of the 1964 Helsinki declaration and its later amendments.

Informed consent. Informed consent was obtained from all individual participants included in the study. 


\section{Keywords}

participation; engagement; Family Check-Up; parenting stress; retention

National estimates suggest that $14-20 \%$ of youth experience mental, emotional, or behavioral disorders in any given year, that these problems co-occur in low income contexts, and that they are burdensome on our education, justice, healthcare, and social welfare systems (NRC/IOM, 2009). The combination of genetic and environmental influences, such as limited access to prenatal and preventive care, exposure to environmental toxins, and inadequate nutrition, renders children born into poverty more prone to behavior problems (e.g., Leventhal \& Brooks-Gunn, 2000; Qi \& Kaiser, 2003). From the lens of family stress theory, studies have shown that the accumulation of seemingly mundane daily stressors has lasting, harmful effects for families in poverty due to "stressor pile-up" (e.g., Conger et al., 2002). Economic pressures can be distressing to parents and negatively affect family relationships, parenting, and children's health (Yoshikawa, Aber, \& Beardslee, 2012). Because of the stressor pile-up faced by low-income parents, confronting child behavior problems can become even more of a struggle. Being a member of a marginalized group, which are disproportionally represented in low-income communities, compounds the issue with acculturative and discrimination-based stressors (Murry, Brown, Brody, Cutrona, \& Simons, 2001; White, Roosa, Weaver, \& Nair, 2009).

Over the past several decades, the field of prevention has developed a strong evidence base for the ability of preventive interventions to reduce behavior problems by intervening in early childhood, especially using ecological, family-centered programs (Hawkins et al., 2015). Although national estimates of the number of families accessing preventive services are as of yet unavailable, reports of program recruitment rates have indicated that only one third to one half of invited participants enroll in prevention programs (Garvey, Julion, Fogg, Kratovil, \& Gross, 2006; Winslow, Bonds, Wolchik, Sandler, \& Braver, 2009). Participant engagement has been conceptualized in many ways, including attendance, active participation in sessions, home practice, and satisfaction. Of these, attendance is the most fundamental as it is a necessary precursor to other indicators such as active engagement in sessions, satisfaction, or use of program skills (Berkel et al., this issue). Existing research has been relatively consistent in supporting a link between program participation and positive outcomes (Durlak \& DuPre, 2008). Engaging those families most in need of prevention services is critical to effectively reducing mental and behavioral health conditions throughout the lifespan. In fact, families at higher risk appear to benefit the most from evidence-based programs. However, an engagement paradox exists where, due to multiple stressors and demands on time, families at highest risk may be the least likely to attend program sessions (for a review see Shelleby \& Shaw, 2014).

One complicating methodological issue is that variables such as SES, minority status, mental health, and child behavior problems are not independent from one another (Baker, Arnold, \& Meagher, 2011; Winslow et al., 2009), which makes interpretation of findings related to engagement difficult. For example, some studies have found that lower SES predicted lower attendance (e.g., Peters, Calam, \& Harrington, 2005; Winslow et al., 2009), whereas others 
did not (e.g., Garvey et al., 2006). Managing living in poverty could be associated with more structural barriers to participation, such as inflexible work schedules, lower perceived need for a preventive intervention given other family needs and concerns, and discomfort with inviting someone into the family home (the latter two are attitudinal barriers). The effects of racial/ethnic group membership are similarly inconsistent, with some studies finding that minority group members were less likely to attend (e.g., Winslow et al., 2009), some finding no effect (e.g., Garvey et al., 2006), and another finding that minority group members were more likely to enroll, but not attend a parent training program (Baker et al., 2011). Consistently, baseline risk in terms of child problem behaviors is inversely related to participation (e.g., Baker et al., 2011). Returning to family stress, caregiver's general stress and depression levels are typically associated with greater participation in parenting programs (Morawska \& Sanders, 2006).

Most evidence-based prevention programs for families have taken the format of group-based delivery. Despite some inherent strengths of group delivery (e.g., economizing therapist's time relative to individual meetings with families, taking advantage of group context and processes to promote individuals' behavior change), this format may be especially problematic for low income families due to the coordination of meeting times and the requirement of traveling to delivery sites (Spoth \& Redmond, 1993). Research by Dishion and colleagues suggested that despite the effectiveness of group interventions with parents of high risk youth (Dishion \& Andrews, 1995), engagement of the families most in need into groups was expensive and unrealistic in many community settings. For this reason, a brief, motivational, individualized family intervention, the Family Check-Up (FCU), was designed with the goal of being flexible in terms of context (home, school, clinic), time of day, and participants (mother, father, grandparents) to optimize engagement and increase the public health impact.

In this paper, we examine the participation of families in the FCU program delivered in a home visiting (HV) format, which involves contact with individual families in their own homes. By and large, HV programs are modestly effective at improving the health and behavioral outcomes of children living in disadvantaged homes (Paulsell, Avellar, Sama Martin, \& Del Grosso, 2011; Peacock, Konrad, Watson, Nickel, \& Muhajarine, 2013). The intensity delivered by HV programs often depends on family need, as opposed to being predetermined. Consequently, in the context of the FCU and other HV models, higher levels of risk should be associated with participation in more sessions rather than less due to need. Moreover, the content is tailored to address the most pressing concerns of the family, which has been identified as a critical strategy for retaining parents in parenting programs (Anderson, Kohler, \& Letiecq, 2002). HV may address some of the barriers, most structural, that are most salient to high stress, low-income families (Nievar, Van Egeren, \& Pollard, 2010); however participation in HV is still an issue. In a review of HV programs targeting varied at-risk groups and concerns, Gomby, Culross, and Behrman (1999) found that 10$25 \%$ of invited families choose not to participate, families receive about half of the scheduled number of visits, and 20-76\% terminate the program prematurely. Among the barriers to HV participation are the coordination of caregiver-provider schedules, providercaregiver proximity, and the caregivers' willingness to allow a provider into the home. The 
FCU, when delivered as a HV program, can address some of the problems inherent to groupbased parenting programs and capitalize on the benefits of home-based care.

\section{The Family Check-Up}

The FCU is an ecological approach to family intervention designed to improve children's adjustment across settings (home, school, neighborhood) by motivating positive behavior support and other family management practices. The program comprises three primary contacts with the family: an initial contact session, a multi-informant assessment, and a feedback session. The assessment has an ecological focus and includes questionnaires and a series of brief family videotaped interaction tasks. Salient domains of family management (e.g., positive behavior support, limit setting) are observationally coded from the videotaped interactions and parent-, teacher-, and child-report questionnaire data are collected. Child and caregiver adjustment and mental health factors are also assessed. The feedback session emphasizes parenting and family strengths, yet draws attention to possible areas of change; is intended to help caregivers better understand the ecological factors influencing the child; and enhances the family's motivation to address key problems in parenting either on their own or with professional support. The culmination of the feedback session is the presentation of a menu of intervention options tailored to the specific needs of the family. Most often, caregivers and the FCU therapist will identify a specific issue for which brief support (2-3 sessions) can be provided. When family issues are complex and several issues are occurring simultaneously, it is helpful for follow-up support to be more frequent (e.g., weekly) and more broadly target family management skills. The assessment results drive the number and kind of interventions that are offered to the family.

The FCU has extensive empirical support and is recognized as an evidence-based prevention program (e.g., SAMHSA, 2015) for preventing youth problems and improving child and family adaptation from early childhood through adolescence. The results of studies from the same dataset used in this article revealed significant preventive effects on: problem behaviors (Dishion et al., 2014; Dishion et al., 2008), school readiness (Lunkenheimer et al., 2008), obesity (Smith, Montaño, Dishion, Shaw, \& Wilson, 2015), inhibitory control (Shelleby et al., 2012), and emotional problems (Connell et al., 2008). The program also effectively targets family management practices and family interactional dynamics, as well as caregiver depression, each of which mediate program effects on child outcomes (e.g., Dishion et al., 2008; Lunkenheimer et al., 2008; Shaw, Connell, Dishion, Wilson, \& Gardner, 2009; Smith et al., 2015). With respect to the importance of engagement, Smith, Dishion, Shaw, and Wilson (2013) found that observational ratings of fidelity to the FCU protocol promoted the quality of caregivers' engagement in the FCU feedback session, which was in turn related to subsequent improvements in parenting behaviors and child problem behaviors. Further underscoring the importance of engaging families over time, Dishion and colleagues (2014) found that intervention effects in this trial increased as a function of FCU feedback sessions attended between ages 2 and 5. Last, families with caregivers reporting lower risk were less likely to participate in the FCU in this trial the first time it was offered (Pelham III, Tein, Shaw, Wilson, \& Dishion, 2016). The Pelham et al. study used the same dataset as the current study but only examined initial participation. 


\section{This Study}

Informed by family stress theory, the current study examines participation in the FCU program delivered in the HV format. Families in the intervention arm of the trial were given the option to participate in the FCU program on a yearly basis from ages $2-5$ and again annually from ages $7.5-10.5$ for a total of eight opportunities. We hypothesized that families living in poverty, caregivers indicating the highest levels of perceived parenting stress, conceptualized as daily hassles, psychological distress (depressive symptoms), and negative parenting competency, and children with higher levels of problem behaviors would be associated with greater rates of participation in the FCU. A shortcoming in the literature is that most studies have typically employed overall counts of attendance rather than looking at participation in more theoretically-informed ways (Barrera, Berkel, \& Castro, 2015). Consequently, it is important to examine participation in distinct components of the program in accord with the program's theoretical underpinnings. In this case, engagement was operationalized using two indicators: the total number of feedback sessions attended and the total amount of intervention time received. We examine these indicators concurrently to determine if predictors differentially influence different components of the program. Consistent with the literature, we evaluate the role of racial/ethnic background of the caregiver(s), poverty status, and child behavior problems in the model as potential contributors to the overall level of family stress.

\section{Method}

\section{Participants}

This study examined the 367 families assigned to the intervention arm of a randomized trial testing the efficacy of the FCU program compared to services as usual. The full sample comprised 731 caregiver-child dyads (49\% female children) recruited from WIC in three geographically and culturally diverse U.S. regions near Charlottesville, VA (188 dyads); Eugene, OR (271); and Pittsburgh, PA (272). All families with children between ages 2 years 0 months and 2 years 11 months were screened. Risk criteria for recruitment were defined at or above $1 S D$ above normative averages on screening measures in the following domains: (a) child behavior problems, (b) family problems (e.g., maternal depression, substance-use problems, teen parent status), and (c) sociodemographic risk (e.g., low education achievement, low family income). Those who indicated two or more of the three risk factors were invited to participate. The caregivers who participated at each age were predominantly biological mothers (average of $95 \%$ for ages $2-10.5$ ). The sample was culturally diverse: European American (55.3\%), African American (27.5\%), Latino/Hispanic (11.2\%), and American Indian, Asian American, Native Hawaiian, and multiple ethnicities $(6.0 \%)$. Gross annual family income figures (reported in 2002) averaged less than $\$ 15,000$ $(90.1 \%<\$ 30,000)$ and $21.8 \%$ of the primary caregivers had not achieved a high school education. Intervention families did not differ from those of the full sample in terms on these variables. 


\section{Procedures}

Participants were randomly assigned to either the intervention (367 families) or the control (364 families) condition (WIC services as usual) after the first assessment, which occurred at study entry (age 2) (see CONSORT diagram; Figure 1). Caregivers and children who agreed to participate in the study were scheduled for a 2.5 -hour home visit each year to complete the ecological assessment by trained research staff members. Families were provided a monetary incentive for completion of the assessment. The FCU and follow-up support services were provided free of charge but were not incentivized. Each year the home-based assessment began with a series of age-appropriate interaction tasks. In the intervention arm, the FCU therapist contacted the family after the assessment and offered to meet with them to discuss the findings and develop an individualized intervention plan. Families electing to meet with the FCU therapist were scheduled for an initial interview and rapport building session and feedback (1-2 weeks later). Additional family support services then occurred based on an individualized intervention plan. The sequence of family assessment, initial interview, and feedback was rearranged to protect the integrity of the research design. In real-world practice, the interview occurs before the assessment and feedback sessions.

\section{Measures}

FCU participation-Two indicators representing steps along the continuum of care in the FCU program were used. Consistent with previous FCU studies, the first level of engagement was participation in the FCU feedback session ${ }^{1}$, which is the second contact between the caregiver(s) and the FCU therapist following a brief initial interview. The second indicator was the caregiver(s)' involvement in follow-up support services offered by the FCU provider. Unlike participation in feedback, the offer of follow-up intervention sessions was based on their appropriateness based on the findings of the ecological assessment and the ensuing discussion during feedback. In this study, we calculated the total number of intervention hours, which included services delivered in-person and by phone by the FCU therapist. Services provided by the FCU therapist varied in type (e.g., brief parent training session(s), family therapy, case management) and in terms of the goal or aim of the session (e.g., teach a specific parent management skill, connecting families to available social service resources). Families that did not participate in the FCU feedback also had zero hours of intervention time as feedback was a prerequisite to participating in follow-up support each year. Participation at ages 2, 3, 4, 5, 7.5, 8.5, 9.5, and 10.5 (8 opportunities) were recorded and aggregate scores were calculated.

Caregiver depressive symptomatology-Primary caregivers' initial level of depressive symptomatology was assessed at child age 2 with the 20-item Center for Epidemiological Studies on Depression Scale (Radloff, 1977). Ratings are provided on a scale ranging from 0 (less than a day) to 3 (5-7 days) and are summed. Internal consistency was acceptable $(a=.87)$.

\footnotetext{
${ }^{1}$ As a point of clarification, in previous FCU studies participation in the feedback session has been used to define FCU "engagement" status (e.g., Connell, Dishion, Yasui, \& Kavanagh, 2007; Dishion et al., 2014).
} 
Child noncompliance-Staff completed macro-level ratings of the child's compliance with caregiver directives during the age 2 home assessments using three items: cooperation with the caregiver (reverse scored), dysregulation and difficulty controlling behavior and emotion, and overall compliance (reverse scored) (Dishion, Hogansen, Winter, \& Jabson, 2004). Interrater agreement $(88 \%)$ and internal consistency $(a=.86)$ were high at the age 2 assessment.

Parenting competence-The parenting sense of competency scale is 16-item measure of parental competence that includes two subscales: Efficacy and Satisfaction (GibaudWallston and Wandersman, 1978; as cited in Johnston \& Mash, 1989). The 9-item Satisfaction subscale, which assesses parents' frustration, anxiety, and motivation regarding parenting, was utilized in the current study. Primary caregivers rated items on a 6-point scale $(6=$ strongly agree, $0=$ strongly disagree). Internal consistency at age 2 was acceptable ( $a$ $=.74$ ) for the current sample.

Parenting daily hassles-Primary caregivers completed the Parenting Daily Hassles Questionnaire, a 20-item measure assessing the perceived frequency of hassles and their perceived intensity on a 5-point Likert scale $(1=l o w, 5=h i g h)$. Internal consistency for the perception of daily hassle intensity subscale was $a=.85$ in the current sample at age 2 .

Poverty status-Poverty levels were calculated by adjusting gross household income at age 2 for inflation using the U.S. Department of Labor Bureau of Labor Statistics Consumer Price Index to reflect 2010 levels; $76 \%$ were below the poverty line.

\section{Data Analysis}

Data analysis was conducted in Mplus 7.2 (L. K. Muthén \& Muthén, 2014) using weighted least squares means and variances adjusted — a robust estimator for count data with nonnormally distributed variables (B. O. Muthén, du Toit, \& Spisic, 1997). Model fit indices included the chi-square statistic, comparative fit index (CFI), and the root mean square error of approximation (RMSEA). CFI values greater than 0.93 and RMSEA values less than 0.06 are considered good fit (Hu \& Bentler, 1999). First, we developed a latent construct, parenting stress, with three indictors (caregiver depressive symptoms, parenting satisfaction, daily hassles) and conducted a confirmatory factor analysis (CFA) with the two covariates that were later retained in the path model (poverty status, observed child noncompliance). We then constructed the hypothesized path model in which parenting stress was related to participation in FCU feedback sessions (specified as a count variable) and follow-up intervention time (treated as continuous). Feedback sessions and hours of follow-up intervention time were included in the model simultaneously to control for the direct link between the two. We then tested the significance of the indirect path from child noncompliance to intervention time, via parenting stress and feedback sessions. Wald Tests were used to evaluate moderation by race/ethnicity and trial site.

\section{Results}

Supplemental Table 1 contains the inter-correlations and descriptive statistics of the variables in this study. Participation rates and descriptive statistics for each wave of the trial 
are available in Supplemental Table 2. Families participated in an average of $4.54(S D=$ 2.57) FCU feedback sessions; 24 families $(6.5 \%)$ never participated in a feedback; 69 $(19.8 \%)$ participated in one or two feedbacks; 63 families (17.2\%) participated in all eight FCU feedback opportunities; and, in total, 149 families (40.6\%) participated in 6 or more. Of note, among those families participating in at least one FCU feedback session during the trial $(N=343)$, the majority (82.8\%) received an annual average of less than three hours of follow-up intervention services, while 35 families (10.2\%) averaged greater than five hours per year of follow-up intervention services. Omnibus tests of trial site differences were run to compare the means of participation in FCU feedback and follow-up intervention services. A significant difference was found between sites for follow-up intervention service participation, but not FCU feedback sessions $\left(\chi^{2}(16)=14.376, p=.57\right)$, such that families in Charlottesville, VA participated in fewer hours of intervention per year $(F[2,364]=$ 5.706, $p \leq .01$ (VA: $\mathrm{M}=.93, \mathrm{SD}=1.61 ; \mathrm{OR}: \mathrm{M}=2.18, \mathrm{SD}=3.65 ; \mathrm{PA}: \mathrm{M}=2.91, \mathrm{SD}=$ 6.05). Post hoc Tukey tests indicated that only the Charlottesville and Pittsburgh sites differed significantly on total number of hours. ${ }^{2}$ Concerning families with Non-Latino White caregivers compared to minority racial/ethnic caregivers, there were no mean differences in these variables: feedback sessions, $\chi^{2}(8)=10.061, p=.261$ (White: $\mathrm{M}=4.76$, $\mathrm{SD}=2.61$; Non-White: $\mathrm{M}=4.27, \mathrm{SD}=2.50)$; total intervention time, $F(1,364)=2.454, p$ $=.118$ (White: $\mathrm{M}=2.45, \mathrm{SD}=5.07$; Non-White: $\mathrm{M}=1.72, \mathrm{SD}=3.48$ ).

The CFA model of perceived parenting stress provided good fit to the data, $\chi^{2}(4)=3.459, p$ $=.48, \mathrm{CFI}=1.00, \mathrm{RMSEA}=.00(90 \% \mathrm{CI}=.000 \mid .075), p=.81$. Standardized factor loadings were statistically significant $(p<.01)$ and absolute magnitude ranged from .43 to . 53 , indicating that all factors contributed to the latent construct. Figure 2 contains the standardized path coefficients of the final model. Complete results are presented in Supplemental Table 3. The model provided good fit to the data, $\chi^{2}(8)=4.413, p=.82$, CFI $=1.00, \mathrm{RMSEA}=.00(90 \% \mathrm{CI}=.000 \mid .038), p=.98$. Parenting stress was positively and significantly related to both the number of FCU feedback sessions and hours of follow-up intervention time. The total effect was $\mathrm{B}=.253$, S.E. $=.069, \beta=.313(95 \% \mathrm{CI}=.188 \mid$. 418), $p \leq .001$, compared to the total indirect effect of $\mathrm{B}=.109$, S.E. $=.035, \beta=.135$ (95\% $\mathrm{CI}=.059 \mid .198), p \leq .001$. Living in poverty at age 2 was associated with attending fewer feedback sessions over the course of the trial. Child noncompliance was positively related to higher parenting stress and negatively related to the number of feedback sessions attended. The indirect effect from child noncompliance to intervention time, via parenting stress and FCU feedback sessions, was significant, $\mathrm{B}=.128$, S.E. $=.057, \beta=.025(95 \% \mathrm{CI}=.016 \mid$. $241), p<.05$. The final model accounted for nearly $34 \%$ of the variance in intervention time $(R$-square $=.339, p \leq .001)$.

\section{Moderation}

Tests of moderation were nonsignificant concerning the intervention site (Wald [10] $=11.55$, $p=.24$ ) despite the mean-level differences noted above. However, the strength of the

\footnotetext{
${ }^{2}$ The same pattern was found for in-person intervention time, $F(2,364)=6.241, p \leq .01$ (VA: $\mathrm{M}=1.40, \mathrm{SD}=1.67 ; \mathrm{OR}: \mathrm{M}=2.41$, SD $=3.34 ;$ PA: $\mathrm{M}=3.34, \mathrm{SD}=5.71$ ) where only VA and PA differed but Charlottesville was significantly lower than both Pittsburgh and Eugene on number of intervention contacts from the FCU provider, $F(2,364)=5.865, p \leq .01$ (VA: $\mathrm{M}=1.28, \mathrm{SD}=1.64 ; \mathrm{OR}: \mathrm{M}=$ $2.84, \mathrm{SD}=3.77 ; \mathrm{PA}: \mathrm{M}=2.71, \mathrm{SD}=4.53$ ).
} 
relationship between total feedback sessions and number of treatment hours path was found to be significantly stronger for families with Non-Latino White caregivers compared to racial/ethnic minority caregivers (Wald $[1]=5.61, p<.05$ ). However, probing this difference revealed that this link was weakest for Hispanic/Latino families compared to families of other racial/ethnic backgrounds (Wald [1] $=15.76, p<.001$ ). Mean differences were not significant for feedbacks $\chi^{2}(8)=8.01, p=.424$ (Hispanic/Latino: $\mathrm{M}=3.90, \mathrm{SD}=2.73$; Other race/ethnicity: $\mathrm{M}=4.62, \mathrm{SD}=2.55)$ and approached significance for intervention time, $F(1,365)=3.514, p=.062$ (Hispanic/Latino: $\mathrm{M}=.90, \mathrm{SD}=.94$; Other race/ethnicity: $\mathrm{M}=2.27, \mathrm{SD}=4.68$ )

\section{Post hoc analyses}

Two considerations suggested a need to conduct follow-up analyses to ensure the robustness of our findings. First, families in Virginia having participated in fewer hours suggests that the rural geography or a site variation in FCU delivery might have affected the number of intervention contacts between families and the FCU therapist, not the number of total hours. Similarly, there is also a potential difference between phone and in-person contact in terms of the characteristics of families that would opt for one or the other and in terms of the therapeutic quality of the two modalities. Thus, we ran the final model with total intervention contacts and in-person time as the variables of participation and again examined moderation by site. Both models showed the same pattern of relationships as the final model reported above. Higher perceived parenting stress was positively and significantly related to total number intervention contacts $(\mathrm{B}=.873$, S.E. $=.45, \beta=.155(95 \% \mathrm{CI}=.007 \mid .303), p$ $<.05)$ and in-person intervention time $(\mathrm{B}=.130$, S.E. $=.054, \beta=.262(95 \% \mathrm{CI}=.047 \mid$. 298), $p<.01)$. Both post hoc models and were not moderated by the intervention site (Contacts: Wald [10] $=12.36, p=.18$; In person time: Wald [10] $=9.942, p=.33$ ).

We also tested moderation by urbanicity, an index of the population density based on geocoding of individual family zip codes to better illuminate the heterogeneity between sites. Mean urbanicity scores indicated that Pittsburgh was significantly more urban $(\mathrm{M}=$ 3.12, $\mathrm{SD}=1.007)$, compared to Eugene $(\mathrm{M}=2.48, \mathrm{SD}=.818)$ and Charlottesville $(\mathrm{M}=$ $1.70, \mathrm{SD}=.902), F(2,364)=67.587, p<.001$. The test did not indicate moderation of the paths in the model. Thus, urbanicity does not explain site variation.

\section{Discussion}

In this study we sought to evaluate participation over time in FCU program intervention services and examine the relationships between participation rates and caregiver and family characteristics assessed at study entry. Although all families enrolled in the trial were considered at-risk based on the screening criteria, our findings indicated that there was wide variation in the rate of participation in FCU services over the 8-year period of the Early Steps multisite trial. A small proportion of families, less than 7\%, who were offered the FCU never elected to participate, while more than $40 \%$ of families participated in at least six of the eight opportunities to receive feedback. Similarly, participation in follow-up intervention services varied widely with the vast majority of families receiving less than three total hours on average each year, but a handful of families averaging more than five hours annually. 
Our analyses revealed some of the ecological correlates of these two conceptually relevant indices of participation. Family stress theory posits that the accumulation of parentingrelated stressors and SES-related adversity (i.e., poverty) is related to more severe child problem behaviors, ineffective parting practices, and poor family relationships (Conger et al., 2002; Leventhal \& Brooks-Gunn, 2000; Yoshikawa et al., 2012). These individual indicators are highly interrelated and have been found to affect participation in preventive interventions, but not in a consistent manner. Supporting our hypothesis that higher levels of stress would be associated with greater levels of attendance, we found that the perceived severity of caregiver stress at study entry (child age 2) was positively associated with increased participated in FCU feedback sessions and total hours of intervention time over the course of the Early Steps trial. This is consistent with previous literature demonstrating a fairly robust link between general stress and depressive symptoms with participation in parenting interventions (Morawska \& Sanders, 2006).

The perception of economic hardship for families in low-income environments is a key variable in family stress theory. Although the effect varies, it has been shown to independently relate to parents' distress, family management ability, and children's mental and behavioral health, so we examined poverty status separately. Living in poverty at study entry was related to participating in fewer FCU feedback sessions but was not significantly related to total intervention time. It could be that families in poverty are unable to prioritize an elective program, such as the FCU, due to the challenge of inflexible work schedules and the prioritization of meeting basic needs, such as securing food and safe housing.

Consistent with some previous research, children with higher levels of problem behaviors predicted less participation in the program (see Shelleby \& Shaw, 2014). However, we found that when a noncompliant child was coupled with a caregiver reporting higher distress, participation in the FCU was higher, suggesting that stress is a more salient predictor of elective participation than the child's problem behaviors. These findings underscore the need to examine predictors of engagement in a multivariate framework, which also has implications for family stress theory as it has the potential to illuminate the unique and compounding contribution of different stressors on participation in preventive interventions.

We were surprised to find significant site differences in participation. At the mean level, families recruited near Charlottesville, VA participated in fewer total hours of intervention compared to families at the other sites. Analysis of moderation by intervention site did not reveal any significant differences in the paths in our model, suggesting that the strength of the relationships between the variables is consistent across sites. Post hoc analyses of different metrics of participation (in-person time and number of visits) mirrored these results with no moderation in the path model but mean-level differences indicating lower participation in Charlottesville. One potential explanation for this finding is that the Charlottesville site is more rural than the other sites, which could be related to larger distances between the families' residences and the intervention providers. Since the average number of feedback sessions did not differ, it could be that distance was a factor that reduced the parents' and/or the therapists' willingness to engage in follow-up services. Unfortunately, we do not have data on distance to families' homes readily available to test this hypothesis. 
A potential confounder with this explanation is the heterogeneity within sites in terms of the urbanicity (population density). However, urbanicity also was not found to moderate the paths in our model, which suggests that a more systematic issue could explain the site differences. Fidelity to the FCU protocol, which we have found to relate to caregivers' insession engagement (Smith et al., 2013), is a plausible explanation. However, the level of fidelity to the FCU feedback session, and drift in fidelity, did not differ by site over a fouryear period (Chiapa et al., 2015). Unmeasured differences in other aspects of the program, such as the delivery of follow-up services, the way in which families were approached and offered services, or the components that were delivered might play a role.

Concerning racial/ethnic differences, there were no differences in the mean-level of feedback sessions or intervention hours that families from different groups participated in, which is consistent with previous research on the FCU program in early childhood (the same sample used in this study) and early adolescence (e.g., Connell et al., 2007; Dishion et al., 2014). This has been an inconsistent relationship in the broader literature concerning groupbased parent training (Baker et al., 2011; Winslow et al., 2009) and HV programs (e.g., Nix, Bierman, McMahon, \& Conduct Problems Prevention Research Group, 2009). An interesting finding occurred in our analyses showing that the path between feedback sessions and intervention time was weaker for Latino/Hispanic families compared to all other groups. The size of this group, $11.2 \%$ of the sample, renders any conclusions tentative due to power and generalizability concerns. Although we cannot say for certain what accounts for this difference, anecdotally we found that the two prominent Latino/Hispanic populations in this sample (Eugene and Pittsburgh) were most concerned with securing basic resources; thus, potentially placing a lower priority on participation in an elective parenting intervention. The majority of these families were recently immigrated suggesting that low acculturation could also be related to the relationship between attending feedbacks and continuing intervention services (see White et al., 2009). Additional research is needed but these data suggest that engagement and retention strategies ought to be tailored for acculturation status and programs could incorporate elements that align with the concerns of these families so that they see the need for participation. The FCU currently employs strategies to engage Latino/ Hispanic families, such as offering sessions and materials in Spanish and from bilingual Latino/Hispanic facilitators whenever possible, which were suggested by Mendez and Westerberg (2012). Other aspects of the FCU that make it a cultural responsive intervention are described by Smith, Knoble, Zerr, Dishion, and Stormshak (2014).

\section{Limitations}

Among this study's strengths are its large randomized multisite and ethnically diverse sample, inclusion of pertinent covariates, and a sophisticated analytic approach. However, it is necessary to note certain limitations of the sample and of this particular study. Although an important aspect of participation and engaging families, this study did not specifically examine factors of the FCU program that could account for differential participation rates, such as fidelity to specific clinical components targeting engagement (e.g., motivational interviewing techniques) or differences in the strategies used by therapists to engage families in follow-up parenting support sessions. Nor did we examine therapist factors or therapeutic process factors. For example, a study of families in the Fast Track Program found that better 
therapeutic engagement between parent and therapist predicted participation (Orrell-Valente et al., 1999). Relatedly, therapists' ability to manage caregiver resistance (e.g., Patterson \& Chamberlain, 1994) could be related to participation. These data were either not collected or, in the case of fidelity ratings, are not available for the entire sample in the intervention arm of the trial. Concerning the analytic strategy, although we were interested in participation in the FCU program throughout the eight years of the Early Steps trial, we aggregated the participation data across the years. There could be a dynamic interactional process between need for services and participation that varies over time. Similarly, we used a relatively global index of service hours that included both in-person and phone-based delivery across multiple content areas. This choice somewhat obscures the precision of what types of sessions, or the number of sessions, are related to parenting stress. The findings of our post hoc analyses indicate that the relationship between parenting stress and participation is robust across these different metrics.

\section{Directions for Future Research}

Future research ought to focus on additional specificity and the assessment of data that could explain the relationships found. Concerning specificity, longitudinal models that are capable of accounting for change in variables indicating need for intervention, whether they are naturally occurring or affected by the FCU intervention, could be used. For example, we have found intervention effects in this trial on maternal depressive symptoms between child ages 2 and 3 (Shaw et al., 2009), which could affect participation in later years. There is also another level of engagement germane to the FCU program-participation in communitybased services. Leijten and colleagues (2014) evaluated community service usage for families in the Early Steps trial and found that families assigned to the FCU condition accessed significantly more services in the community at age 7.5 (following trial participation from ages 2 to 5) compared to control families. It is an explicit goal of the FCU to connect families to services in the community. HV programs have been found to increase family's utilization of community-based services, such as healthcare, welfare agencies, and community mental health (Fergusson, Grant, Horwood, \& Ridder, 2005). Last, other salient variables to participation and retention that could be collected and included in future research are process variables (therapists' management of resistance, fidelity to the FCU model, therapeutic alliance) and potential barriers. HV programs reduce many of the structural barriers to participation but attitudinal barriers could still remain that are general to prevention interventions or parenting programs, or are specific to HV (e.g., inviting a mental health professional into your home). These should be assessed with greater precision.

\section{Concluding Remarks}

The inability to engage and retain caregivers in family-centered prevention programs not only threatens the effectiveness and potential public health impact of EBIs (National Institute of Mental Health, 2001), but is also costly for providers and service delivery systems. Given that caregivers with multiple interrelated stressors are more likely to participate, the strategies used to engage families might need to be broader than solely focusing on improving child behaviors. In a review, Ingoldsby (2010) identified only a few interventions that had long-term impacts on engagement and retention. Those that successfully integrated motivational interviewing, a family systems perspective, and used 
enhanced family stress and coping support strategies at multiple points throughout the intervention. Each of these is characteristic of the FCU and its ecological perspective. The results of this study indicate that the Early Steps trial was successful at engaging caregivers with high levels of perceived parenting stress but less successful overall with families living in poverty. Additional research is needed to better understand the precise barriers families in poverty experience when it comes to participation in prevention programs and what delivery and engagement strategies would effectively address these barriers. Results of this study contribute to the literature by using theory to demonstrate that the FCU, delivered as a HV, was effective at engaging those who could benefit the most from a parenting support service.

\section{Supplementary Material}

Refer to Web version on PubMed Central for supplementary material.

\section{Acknowledgments}

This research was supported by National Institute on Drug Abuse grant DA016110 to the third, fourth, and fifth authors. Justin Smith and Cady Berkel were supported by Justin Smith was also supported by National Institute on Drug Abuse grant DA027828 to C. Hendricks Brown. The authors also gratefully thank Charlotte Winter and Shannon McGill for assistance with the data management, the Early Steps team in Eugene, Pittsburgh, and Charlottesville, and the families who have participated in the study.

\section{References}

Anderson EA, Kohler JK, Letiecq BL. Low-income fathers and "Responsible Fatherhood" programs: A qualitative investigation of participants' experiences. Family Relations. 2002; 51(2):148-155.

Baker CN, Arnold DH, Meagher S. Enrollment and attendance in a parent training prevention program for conduct problems. Prevention Science. 2011; 12(2):126-138. [PubMed: 21052834]

Berkel C, Sandler IN, Brown CH, Gallo C, Mauricio AM, Wolchik SA, Jones S. "Home practice is the program": Correlates of parents' practice of program skills in the New Beginnings Program effectiveness trial. Prevention Science. this issue.

Chiapa A, Smith JD, Kim H, Dishion TJ, Shaw DS, Wilson MN. The trajectory of fidelity in a multiyear trial of the Family Check-Up predicts change in child problem behavior. Journal of Consulting and Clinical Psychology. 2015; 83(5):1006-1011. [PubMed: 26121303]

Conger RD, Wallace LE, Sun Y, Simons RL, McLoyd VC, Brody GH. Economic pressure in African American families: A replication and extension of the family stress model. Developmental Psychology. 2002; 38(2):179-193. [PubMed: 11881755]

Connell AM, Bullock BM, Dishion TJ, Shaw DS, Wilson MN, Gardner FEM. Family intervention effects on co-occurring early childhood behavioral and emotional problems: A latent transition analysis approach. Journal of Abnormal Child Psychology. 2008; 36(8):1211-1225. [PubMed: 18473160]

Connell AM, Dishion TJ, Yasui M, Kavanagh K. An adaptive approach to family intervention: Linking engagement in family-centered intervention to reductions in adolescent problem behavior. Journal of Consulting and Clinical Psychology. 2007; 75(4):568-579. [PubMed: 17663611]

Dishion TJ, Andrews DW. Preventing escalation in problem behaviors with high-risk young adolescents: Immediate and 1-year outcomes. Journal of Consulting and Clinical Psychology. 1995; 63(4):538-548. [PubMed: 7673531]

Dishion TJ, Brennan LM, Shaw DS, McEachern AD, Wilson MN, Jo B. Prevention of problem behavior through annual Family Check-Ups in early childhood: Intervention effects from home to early elementary school. Journal of Abnormal Child Psychology. 2014; 42(3):343-354. [PubMed: 24022677] 
Dishion TJ, Hogansen J, Winter C, Jabson JM. The Coder Impressions Inventory. Unpublished coding manual. Available from the Child and Family Center, 6217 University of Oregon, Eugene, OR 97403. 2004

Dishion TJ, Shaw DS, Connell A, Gardner FEM, Weaver C, Wilson M. The Family Check-Up with high-risk indigent families: Preventing problem behavior by increasing parents' positive behavior support in early childhood. Child Development. 2008; 79(5):1395-1414. [PubMed: 18826532]

Durlak JA, DuPre EP. Implementation matters: A review of research on the influence of implementation on program outcomes and the factors affecting implementation. American Journal of Community Psychology. 2008; 41(3-4):327-350. [PubMed: 18322790]

Fergusson DM, Grant H, Horwood LJ, Ridder EM. Randomized Trial of the Early Start Program of Home Visitation. Pediatrics. 2005; 116(6):e803-e809. [PubMed: 16322138]

Garvey C, Julion W, Fogg L, Kratovil A, Gross D. Measuring participation in a prevention trial with parents of young children. Research in Nursing \& Health. 2006; 29(3):212-222. [PubMed: 16676341]

Gomby DS, Culross PL, Behrman RE. Home Visiting: Recent Program Evaluations: Analysis and Recommendations. The Future of Children. 1999; 9(1):4-26.

Hawkins JD, Jenson JM, Catalano RF, Fraser MW, Botvin GJ, Shapiro V, Stone S. Unleashing the Power of Prevention. 2015 Retrieved from Washington, DC:

$\mathrm{Hu}$ L, Bentler PM. Cutoff criteria for fit indexes in covariance structure analysis: Conventional criteria versus new alternatives. Structural Equation Modeling: A Multidisciplinary Journal. 1999; 6(1):155 .

Ingoldsby EM. Review of interventions to improve family engagement and retention in parent and child mental health programs. Journal of Child and Family Studies. 2010; 19(5):629-645. [PubMed: 20823946]

Johnston C, Mash EJ. A measure of parenting satisfaction and efficacy. Journal of Clinical Child Psychology. 1989; 18(2):167-175.

Leijten P, Shaw DS, Gardner FEM, Wilson MN, Matthys W, Dishion TJ. The Family Check-Up and service use in high-risk families of young children: A prevention strategy with a bridge to community-based treatment. Prevention Science. 2014; 16(3):397-406.

Leventhal T, Brooks-Gunn J. The neighborhoods they live in: the effects of neighborhood residence on child and adolescent outcomes. Psychological Bulletin. 2000; 126(2):309. [PubMed: 10748645]

Lunkenheimer ES, Dishion TJ, Shaw DS, Connell AM, Gardner FEM, Wilson MN, Skuban EM. Collateral benefits of the Family Check-Up on early childhood school readiness: Indirect effects of parents' positive behavior support. Developmental Psychology. 2008; 44(6):1737-1752. [PubMed: 18999335]

Mendez JL, Westerberg D. Implementation of a culturally adapted treatment to reduce barriers for Latino parents. Cultural Diversity and Ethnic Minority Psychology. 2012; 18(4):363-372. [PubMed: 22866691]

Morawska A, Sanders M. A review of parental engagement in parenting interventions and strategies to promote it. Journal of children's services. 2006; 1(1):29-40.

Murry VM, Brown PA, Brody GH, Cutrona CE, Simons RL. Racial discrimination as a moderator of the links among stress, maternal psychological functioning, and family relationships. Journal of Marriage and Family. 2001; 63(4):915-926.

Muthén, BO., du Toit, SHC., Spisic, D. Robust inference using weighted least squares and quadratic estimating equations in latent variable modeling with categorical and continuous outcomes. Unpublished technical paper. 1997. Retrieved from http://www.statmodel.com/papers.shtml

Muthén, LK., Muthén, BO. Mplus user's guide (Version 7.2). Los Angeles, CA: Muthén \& Muthén; 2014.

National Institute of Mental Health. Blueprint for change: Research on Child and Adolescent Mental Health's Council's Workgroup on Child and Adolescent Mental Health Intervention Development and Deployment (DHHS Publication No. CG 031-591). 2001

Nievar MA, Van Egeren LA, Pollard S. A meta-analysis of home visiting programs: Moderators of improvements in maternal behavior. Infant Mental Health Journal. 2010; 31(5):499-520.

[PubMed: 28543835] 
Nix RL, Bierman KL, McMahon RJ. Conduct Problems Prevention Research Group. How attendance and quality of participation affect treatment response to parent management training. Journal of Consulting \& Clinical Psychology. 2009; 77(3):429-438. [PubMed: 19485585]

NRC/IOM. Preventing Mental, Emotional, and Behavioral Disorders among Young People: Progress and Possibilities. 2009 Retrieved from Washington, D.C.:

Orrell-Valente JK, Pinderhughes EE, Valente E, Laird RD, Bierman KL, Coie JD, McMahon RJ. If it's offered, will they come? Influences on parents' participation in a community-based conduct problems prevention program. American Journal of Community Psychology. 1999; 27(6):753783. [PubMed: 10723534]

Patterson GR, Chamberlain P. A functional analysis of resistance during parent training therapy. Clinical Psychology: Science and Practice. 1994; 1:53-70.

Paulsell, D., Avellar, S., Sama Martin, E., Del Grosso, P. Home visiting evidence of effectiveness review: Executive summary. 2011. Retrieved from http://www.acf.hhs.gov/sites/default/files/opre/ homvee_executivesummary_rev10_15_2011.pdf

Peacock S, Konrad S, Watson E, Nickel D, Muhajarine N. Effectiveness of home visiting programs on child outcomes: A systematic review. BMC Public Health. 2013; 13(1):1-14. [PubMed: 23280303]

Pelham WE III, Tein J-Y, Shaw DS, Wilson MN, Dishion TJ. What doesn't work for whom? Predicting responsiveness to the Family Check-Up in early childhood using a mixture model approach. Manuscript submitted for publication. 2016

Peters S, Calam R, Harrington R. Maternal attributions and expressed emotion as predictors of attendance at parent management training. Journal of Child Psychology \& Psychiatry. 2005; 46(4): 436-448. [PubMed: 15819652]

Qi CH, Kaiser AP. Behavior problems of preschool children from low-income families: Review of the literature. Topics in Early Childhood Special Education. 2003; 23(4):188-216.

Radloff LS. The CES-D scale. Applied psychological measurement. 1977; 1(3):385-401.

SAMHSA. National Registry of Evidence-Based Programs and Practices. 2015. http:// www.nrepp.samhsa.gov/

Shaw DS, Connell A, Dishion TJ, Wilson MN, Gardner FEM. Improvements in maternal depression as a mediator of intervention effects on early childhood problem behavior. Development and Psychopathology. 2009; 21(02):417-439. [PubMed: 19338691]

Shelleby EC, Shaw DS. Outcomes of parenting interventions for child conduct problems: A review of differential effectiveness. Child Psychiatry \& Human Development. 2014; 45(5):628-645. [PubMed: 24390592]

Shelleby EC, Shaw DS, Cheong J, Chang H, Gardner FEM, Dishion TJ, Wilson MN. Behavioral control in at-risk toddlers: The influence of the Family CheckUp. Journal of Clinical Child \& Adolescent Psychology. 2012; 41(3):288-301. [PubMed: 22494145]

Smith JD, Dishion TJ, Shaw DS, Wilson MN. Indirect effects of fidelity to the Family Check-Up on changes in parenting and early childhood problem behaviors. Journal of Consulting and Clinical Psychology. 2013; 81(6):962-974. [PubMed: 23895087]

Smith JD, Knoble N, Zerr AA, Dishion TJ, Stormshak EA. Multicultural competence and the Family Check-Up: Indirect effect on adolescent antisocial behavior through family conflict. Journal of Clinical Child \& Adolescent Psychology. 2014; 43(3):400-414. [PubMed: 24731120]

Smith JD, Montaño Z, Dishion TJ, Shaw DS, Wilson MN. Preventing weight gain and obesity: Indirect effects of a family-based intervention in early childhood. Prevention Science. 2015; 16(3):408419. [PubMed: 25263212]

Spoth R, Redmond C. Study of participation barriers in family-focused prevention: Research issues and preliminary results. International Quarterly of Community Health Education. 1993; 13(4): 365-388.

White RMB, Roosa MW, Weaver SR, Nair RL. Cultural and contextual influences on parenting in Mexican american families. Journal of Marriage and Family. 2009; 71(1):61-79. [PubMed: 20126298]

Winslow EB, Bonds D, Wolchik S, Sandler I, Braver S. Predictors of enrollment and retention in a preventive parenting intervention for divorced families. The Journal of Primary Prevention. 2009; 30(2):151-172. [PubMed: 19283483] 
Yoshikawa H, Aber JL, Beardslee WR. The effects of poverty on the mental, emotional, and behavioral health of children and youth: implications for prevention. American Psychologist. 2012; 67(4):

272-284. [PubMed: 22583341] 


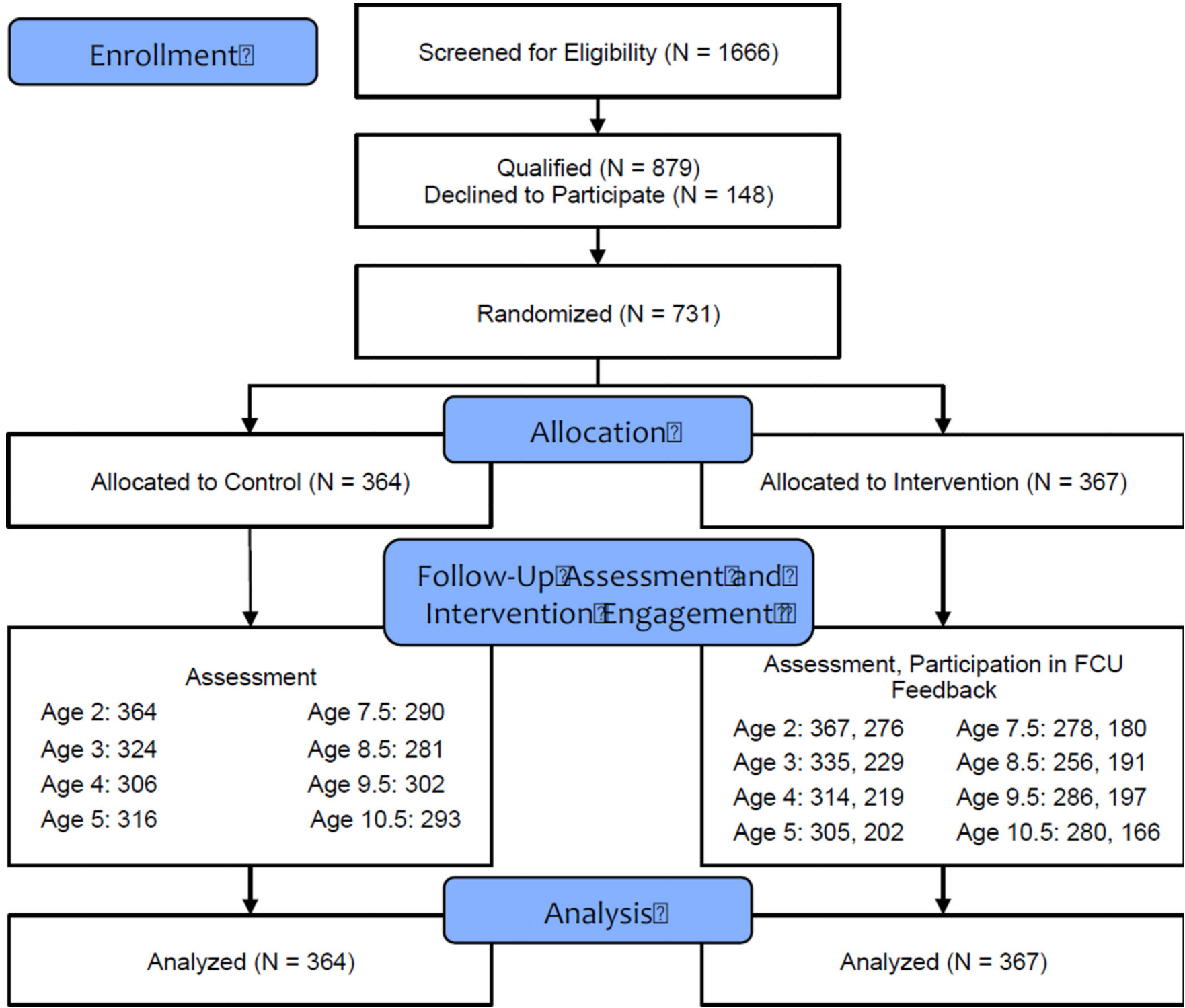

Figure 1. CONSORT flow diagram for all trial participants

Note. This study only reports analyses of families in the intervention arm. 


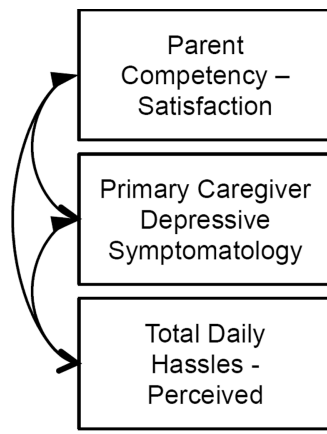

$$
-.42^{\star \star *}(.06)
$$
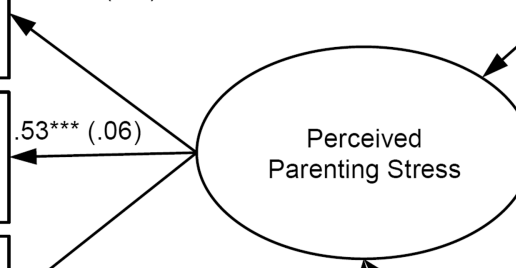

$51^{* * *}(.06)$

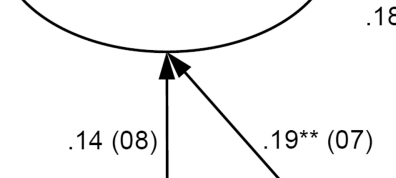

$18 *(08)$
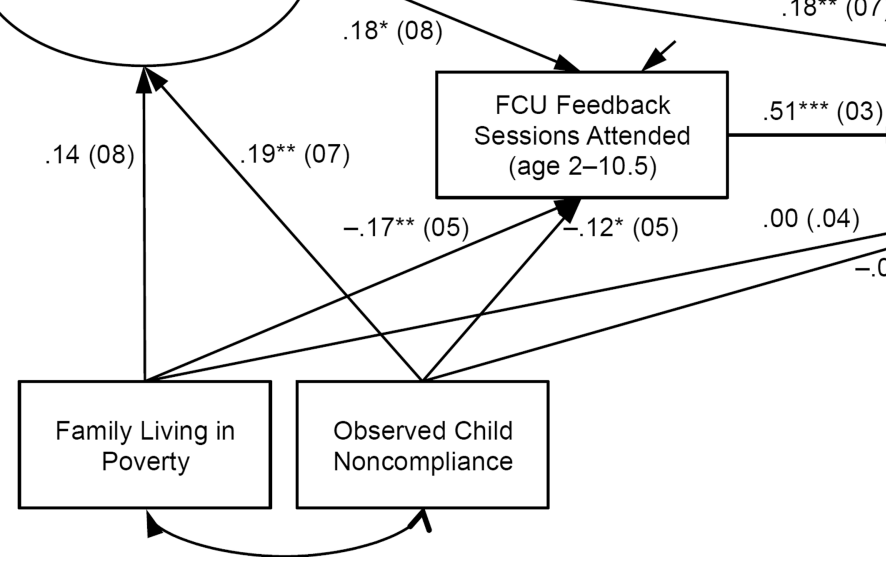

Figure 2. Path Model

Note. ${ }^{*} p<.05 .{ }^{* *} p<.01 .{ }^{* * *} p<.001$ (two-tailed). Standardized path coefficients are provided. Unstandardized coefficients and confidence intervals are available in Supplemental Table 3. Variables assessed at study entry (age 2) unless otherwise specified. 